Background PID is a common condition seen at genitourinary clinics. BASHH published NICE approved guidelines in 2011. To improve consistency amongst clinicians we designed a simple aide memoire tick-box sticker. To improve health adviser (HA) contact and reduce "did-not-attend" (DNA) rates we established a HA staffed telephone follow-up clinic

Methods We regularly audit both management of PID and follow-up and so were able to compare data (2011-2015) to demonstrate improvements in practice with these changes

Outcome Partner notification rates improved from 50\% to $67 \%$ helped mainly by the telephone clinic as HA documented in all cases whether partners had been screened/treated. $82 \%$ had a recording of symptom change, previously 77\%. For those followed-up using the telephone clinic proforma this was $100 \%$. Results for the number of named male contacts screened for infection and/or treated have improved $(2011=0.21 ; 2014=$ $0.38 ; 2015=0.48)$ and we now achieve above the BASHH target $(0.4$ - large city centre clinic). Over the past five years introducing these measures into clinic has improved all outcomes except DNA rate which remains stubborn (33\% vs 27\%). For a large city centre clinic the reasons behind this are complex and varied

Conclusions Innovative yet simple measures can be easily introduced which have a positive impact on guideline adherence and also make audit an easier task. With the advent of EPR in many clinics these initiatives should be transferable and aid standardising management across the GU network particularly during this time of change and service integration

\section{P051 AN AUDIT OF BLOODBORNE VIRUS SCREENING AND SAFER SEX ADVICE FOR SEX WORKERS}

Luke Cannon*, Cara Saxon, Sameena Ahmad. University Hospital South Manchester, Manchester, UK

\subsection{6/sextrans-2016-052718.105}

Background/introduction Commercial Sex Workers (CSW) are at increased risk of STIs including Hepatitis B virus (HBV) and, for some, Hepatitis $\mathrm{C}$ virus (HCV) and sexual assault. These risks can be reduced by vaccination, post-exposure prophylaxis (PEP) awareness and condoms.
Aim(s)/objectives To audit management against clinic policy with respect to documentation of: HBV status; offering vaccination (vacc.) to HBV negative; HCV test; HIV test; PEP information/ awareness and offer of condoms. Additional data was collected on new/prior STIs, recreational drugs, and same sex contact.

Methods Casenotes of all attenders between 01/01/12 and 30/ 09/15 with a SW code were reviewed and additional data collected regarding vaccine uptake.

Results 56 (7 males (12.5\%), 49 females (87.5\%)) individuals with a total of 243 episodes, with a median of 3 (1-17) visits, were identified. Median age of 30 (range 18-63) with 51 (91\%) of white British ethnicity. 38 (67.9\%) reported an STI diagnosis prior to the period audited and $13(23.2 \%)$ had $\geq 1$ new STI during this period, median 1 (1-3). 21 (37.5\%) reported current/recent use of recreational drugs and 31/54 (57.4\%) documented same sex contact, (including MSM contact for females). PEPSE was issued at 2/243 (0.8\%) of episodes.

Discussion/conclusion The main limitation of the audit was dependence on SW code. Performance was good (>95\%) for HBV documentation at first/subsequent visits, offer of HIV test, whilst HCV testing and documentation re. condoms and PEPSE awareness were suboptimal (45-80\%). None were IVDU, and policy re. HCV testing in CSW will be reviewed given the low positivity rate.

\section{P052 MEN WHO HAVE SEX WITH MEN (MSM) PRESENTING WITH REPEAT BACTERIAL SEXUALLY TRANSMITTED INFECTIONS (STI) REPORT HIGH USE OF ALCOHOL AND PARTY DRUGS}

${ }^{1}$ Rosalind Briggs*, ${ }^{1}$ Fionnuala Finnerty, ${ }^{1}$ Nicolas Pinto Sander, ${ }^{1,2}$ Daniel Richardson. ${ }^{1}$ Brighton \& Sussex University NHS Trust, Brighton, UK; ${ }^{2}$ Brighton \& Sussex Medical School, Brighton, UK

\subsection{6/sextrans-2016-052718.106}

Background/introduction Bacterial sexually transmitted infections (Chlamydia, Gonorrhoea and Syphilis) are increasing in men who have sex with men in the UK. The reasons for this include alcohol and recreational drug use, availability of PrEP and awareness of HIV treatment as prevention, and social media.

Abstract P051 Table 1 Blood borne viruses in sex workers

\begin{tabular}{|c|c|c|c|}
\hline & Test offered & Test accepted & Tested positive \\
\hline HBV at first visit $(n=56)$ & $55(98.2 \%)$ & $55(98.2 \%)$ & $1(\mathrm{eAb}+\mathrm{sAg})$ \\
\hline HCV test (episode, $n=243$ ) & $193(79.4 \%)$ & $176(91 \%)$ & 0 \\
\hline \multirow[t]{2}{*}{ HIV test (episode, $n=243$ ) } & $239(98.4 \%)$ & $222(92.9 \%)$ & 0 \\
\hline & Documented & HBV status at first visit $(n=56)$ & $\begin{array}{l}\text { Outcome of those } \\
\text { with unknown status } \\
\text { at first visit }(n=33)\end{array}$ \\
\hline \multirow[t]{7}{*}{ HBV status (episode, 243) } & $239(98.4 \%)$ & 1 past infection $(1.8 \%)$ & 4 immune (12.1\%) \\
\hline & & 1 chronic HBV (1.8\%) & 7 undergoing vacc. $(21.2 \%)$ \\
\hline & & 20 immune post vac $(35.7 \%)$ & 10 vacc. at first visit $(30.3 \%)$ \\
\hline & & 1 not tested $(1.8 \%)$ & 7 vacc. at later visit $(21.2 \%)$ \\
\hline & & 33 status unknown $(58.9 \%)$ & 3 declined vacc, $(9.1 \%)$ \\
\hline & & & 2 did not attend vacc. (6.1\%) \\
\hline & Documented & Not documented & \\
\hline PEPSE info/awareness (episode, 243) & $111(45.7 \%)$ & $132(54.3 \%)$ & \\
\hline Offered condoms (episode, 243) & $174(71.6 \%)$ & $69(28.4 \%)$ & \\
\hline
\end{tabular}

